\title{
Is bicarbonate stable in and on the calcite surface?
}

\author{
M.P. Andersson*, J.D. Rodriguez-Blanco, S.L.S. Stipp \\ Nano-Science Center, Department of Chemistry, University of Copenhagen, Universitetsparken 5, DK-2100 Copenhagen, Denmark
}

Received 18 August 2015; accepted in revised form 17 December 2015; Available online 22 December 2015

\begin{abstract}
We have used density functional theory with the COSMO-RS implicit solvent model to predict the $\mathrm{p} K_{\mathrm{a}}$ for the deprotonation of bicarbonate to carbonate, i.e. $\mathrm{HCO}_{3}^{-}<=>\mathrm{CO}_{3}^{2-}+\mathrm{H}^{+}$, when $\mathrm{HCO}_{3}^{-}$is included in, and adsorbed on, a calcite surface. We have used cluster models (80-100 atoms) to represent the flat $\{10.4\}$ surface, acute steps, obtuse steps, two types of kinks on the acute step and two types of kinks on the obtuse steps. Based on the predicted $\mathrm{p} K_{\mathrm{a}}$ values, which range from -6.0 to 2.4 depending on the surface site, we conclude that bicarbonate deprotonates to carbonate when it is in calcite even when $\mathrm{pH}$ in solution is very low. This is true for all surface sites, even for solutions where $2.4<\mathrm{pH}<6.35$, where $\mathrm{H}_{2} \mathrm{CO}_{3}^{0}$ is the dominant dissolved species. When bicarbonate is adsorbed on calcite, the predicted $\mathrm{p} K_{\mathrm{a}}$ for deprotonation is 7.5 , which is $\sim 3$ $\mathrm{pH}$ units lower than in aqueous solution, 10.35. This means that adsorbed carbonate is stable even when the concentration of dissolved $\mathrm{CO}_{3}^{2-}$ is several orders of magnitude lower. This has a significant effect on surface charge and thus the behaviour of the calcite surface. Our results help explain the potential determining behaviour of the carbonate species in calcite-water systems, particularly in the $\mathrm{pH}$ range where the bicarbonate species dominates in water and where the carbonate species dominates at the surface, i.e. when $7.5<\mathrm{pH}<10.35$. Our atomic scale data for the various calcite surface sites provide the needed input to improve and constrain surface complexation modelling and are especially useful for predicting behaviour in systems where experiments are difficult or impossible, such as at high temperature and pressure.
\end{abstract}

(c) 2015 Elsevier Ltd. All rights reserved.

\section{INTRODUCTION}

Calcite and aragonite $\left(\mathrm{CaCO}_{3}\right)$ are ubiquitous in nature and frequently form by biomineralization, playing a key role in the global carbon cycle (Reeder, 1992) (MacKenzie and Andersson, 2013). During the formation and dissolution of carbonate minerals, the addition and removal of $\mathrm{Ca}^{2+}$ and $\mathrm{CO}_{3}^{2-}$ ions at the crystal surface are governed by three main variables: temperature, saturation state and $\mathrm{pH}$ of the solution. $\mathrm{pH}$ is particularly important because it controls the speciation of carbonate and the solubility of carbonate minerals, thus the rate of dissolution and crystallization. Seawater has an average $\mathrm{pH}$ of 8.3 , at which the bicarbonate ion $\left(\mathrm{HCO}_{3}^{-}\right)$is the most abundant

\footnotetext{
* Corresponding author.

E-mail address: ma@nano.ku.dk (M.P. Andersson).
}

aqueous species (Millero, 2003) and the concentrations of carbonate $\left(\mathrm{CO}_{3}^{2-}\right)$ and carbonic acid $\left(\mathrm{H}_{2} \mathrm{CO}_{3}\right)$ are equal and two orders of magnitude lower. Little is known about the specific role of $\mathrm{HCO}_{3}^{-}$in the molecular scale mechanisms of calcite growth and dissolution, despite the importance of carbonate minerals in the biogeochemistry of present and past oceans and decades of research on the $\mathrm{CaCO}_{3}-\mathrm{CO}_{2}-\mathrm{H}_{2} \mathrm{O}$ system.

Bicarbonate is essential in biomineralization, including the metabolic activity of marine microorganisms. Coccolithophorids, one of the most important groups of marine biomineralising phytoplankton, make calcite shields using $\mathrm{HCO}_{3}^{-}$, that is directly absorbed from sea water. (Nimer and Merrett, 1992; Paasche et al., 1996; Nimer et al., 1997) This ability has provided them with a competitive advantage over other phytoplankton, that can only use $\mathrm{CO}_{2}$ for their biochemical processes. On the whole, metabolic activity of organisms during the past 600 million years 
has resulted in the buildup of massive deposits of calcite in marine sediments worldwide and decreased the partial pressure of $\mathrm{CO}_{2}$ in the atmosphere (Berner, 1990). Nevertheless, the precise mechanisms that determine how $\mathrm{HCO}_{3}^{-}$ is incorporated into biogenic calcite at the nano and atomic scale are poorly understood. Mechanistic insight into the relationship between the various carbonate species and the surface of calcite would be a big step forward.

$\mathrm{X}$-ray techniques have been used to characterise the molecular scale properties of the calcite surface (Stipp and Hochella, 1991; Fenter et al., 2000; Fenter and Sturchio, 2004; Bohr et al., 2010). Fenter et al. performed $\mathrm{X}$-ray reflectivity experiments and found water adsorbed to the surface Ca ions (Fenter et al., 2000). They concluded that the water only began to dissociate to hydroxyl above $\mathrm{pH} \sim 12$. On the contrary, Stipp and Hochela used X-ray photoelectron spectroscopy and presented evidence of calcium and carbonate association with water. The conclusions from the experiments thus vary somewhat but indicate that some degree of water dissociation occurs, producing hydroxyl. Density functional theory modelling predicts that no dissociation occurs on ideal calcite $\{10.4\}$ surfaces (Lardge et al., 2009; Andersson and Stipp, 2012), but the propensity for water dissociation on defect sites is significantly higher (Lardge et al., 2010; Andersson and Stipp, 2012). Considering the solid solution potential for other ions in calcite and the frequency of dislocations in the bulk and step edges on the surfaces, there is no shortage of defects in a real sample. Concurrently with experimental work, surface complexation models have been developed (Morse, 1986; Van Cappellen et al., 1993; Fenter et al., 2000; Pokrovsky et al., 2000; Villegas-Jimenez et al., 2009). These take into account the various protonation states of ions on and in the surface, such as bicarbonate and carbonate, as well as water and hydroxyl ions. In order to use such a model, the species to include are selected and then a fit is made to some experimental properties, e.g. a titration curve of surface charge vs solution $\mathrm{pH}$. Both experimental work and surface complexation modelling capture the average behaviour of the surface, which in the case of calcite is completely dominated by the $\{10.4\}$ plane. Molecular modelling, as we describe in this paper, can provide insight into how the various surface sites contribute to the average behaviour which is not directly accessible in experiments.

In spite of all of the work done on surface complexation, little experimental research has been aimed at identifying the effects of the $\mathrm{HCO}_{3}^{-}$ion in the rates and mechanisms of calcite growth and dissolution. The effect of $\mathrm{HCO}_{3}^{-}$on calcite dissolution was investigated using atomic force microscopy combined with analytical models and kinetic Monte Carlo simulations (Liang et al., 1996). Another study showed that the thermodynamics for dissolution of the obtuse and the acute steps of calcite were different (de Leeuw et al., 1999). Most of the growth studies have consisted of synthesising inorganic calcite at various degrees of supersaturation and various $\mathrm{Ca}^{2+}: \mathrm{HCO}_{3}^{-}: \mathrm{CO}_{3}^{2-}$ ratios (Reddy et al., 1981; Cassford et al., 1983; Przybylinski, 1987; van der Weijden et al., 1997; Duffy et al., 2005; Larsen et al., 2010a,b; Gebrehiwet et al., 2012).
Przybylinski (1987) observed that $\mathrm{HCO}_{3}^{-}$promoted the growth of calcite and the uptake of foreign ions in seeded experiments and also that the growth rate was proportional to supersaturation. Van der Weijden et al. (1997) suggested that this proportionality between supersaturation and the kinetics of calcite growth would be a consequence of a more substantial contribution of $\mathrm{HCO}_{3}^{-}$to the growth process. According to Przybylinski (1987), bicarbonate would favour the transport of carbonate through the boundary layers close to the surface. These hypotheses are consistent with the higher diffusion coefficient for $\mathrm{CO}_{2(\mathrm{aq})}$ and $\mathrm{HCO}_{3}^{-}$ compared with the $\mathrm{CO}_{3}^{2-}$ ion, which has been predicted (Zeebe, 2011) using molecular dynamics simulations. It would also explain other behaviour, such as the shorter time required to isotopically equilibrate calcite at lower pH (Zeebe and Wolf-Gladrow, 2001).

The observations that have been reported so far could be better explained by knowing how stable the $\mathrm{HCO}_{3}^{-}$ion is on the surface of calcite. NMR spectroscopy has shown that $\mathrm{HCO}_{3}^{-}$on natural (biogenic and abiogenic) and synthetic calcite, that is precipitated at ambient temperature, (Feng et al., 2006) is usually present in small quantities $(<1 \%)$ but the signal from $\mathrm{HCO}_{3}^{-}$is stronger when calcite had coprecipitated with phosphate and organic molecules. Bicarbonate could be on the surface and within the crystal and it could be associated with fluid inclusions. This suggests that the monoprotonation of carbonate could be an important aid for accommodating defects in the calcite crystal. Therefore, $\mathrm{HCO}_{3}^{-}$substitution could serve as a local charge balance mechanism near large defects or mosaic boundaries. However, obtaining information about the stability of the $\mathrm{HCO}_{3}^{-}$ion on the surface of calcite and also identifying which nanoscale processes are at play, requires using approaches such as classical molecular dynamics (Lasaga and Luttge, 2001; De Yoreo et al., 2009). Our aim was to shed light on the molecular nature of the surface sites at equilibrium.

Molecular modelling of calcium carbonate growth has primarily used classical force fields (Tribello et al., 2009; Raiteri and Gale, 2010) but a reactive force field has been developed for calcite that is able to treat protonation and deprotonation (Gale et al., 2011). This would be particularly useful for understanding the early stages of the growth and nucleation that might involve more complex processes than simple addition of ions, such as liquid-liquid separation (Wallace et al., 2013).

In this paper, we have chosen to use a first principles approach to predict the surface $\mathrm{p} K_{\mathrm{a}}$ for bicarbonate deprotonation to carbonate. First principles methods require fewer empirical parameters and are more consistently transferable. Compared with surface complexation models, this has the distinct advantage that no fit to experimental data is required and it also allows us to investigate surface sites, for which experimental data cannot be collected. We have previously used this approach to predict the $\mathrm{p} K_{\mathrm{a}}$ of water adsorbed to $\mathrm{Ca}$ ions in the calcite surface and shown that the acidity of water is strongly affected by the geometry of the adsorption site. We found that all surface Ca sites have a lower $\mathrm{p} K_{\mathrm{a}}$ than a hydrated $\mathrm{Ca}^{2+}$ ion in solution and in particular, water on kink sites bridging two $\mathrm{Ca}^{2+}$ ions 
has a $\mathrm{p} K_{\mathrm{a}}$ as low as 3-4. Hence $\mathrm{OH}^{-}$would be more stable on these sites at neutral $\mathrm{pH}$ than intact water (Andersson and Stipp, 2012). Importantly, our predicted $\mathrm{p} K_{\mathrm{a}}$ for water adsorbed on the $\{10.4\}$ surface agrees quite well with results from surface complexation models, (Morse, 1986; Van Cappellen et al., 1993; Fenter et al., 2000; Pokrovsky et al., 2000; Villegas-Jimenez et al., 2009) which provides confidence in our modelling approach.

There are two major questions however, that arise from previous work: i) does bicarbonate in calcite exist as an intact species or does deprotonation follow immediately after adsorption? and ii) does a tendency to deprotonate depend on the nature of the binding site?

To answer these questions, we predicted the $\mathrm{p} K_{\mathrm{a}}$ for $\mathrm{HCO}_{3}^{-}$deprotonation, when the ion occupies the various calcite surface sites. In addition, we have predicted the $\mathrm{p} K_{\mathrm{a}}$ for $\mathrm{HCO}_{3}^{-}$adsorbed on the most stable calcite face, $\{10.4\}$, both in outer and inner sphere configurations.

The aim of our study was to determine how calcite surface site coordination affects the stability of adsorbed $\mathrm{HCO}_{3}^{-}$and to understand the consequences this has on surface charge as a function of $\mathrm{pH}$. Another goal was to describe equilibrium surface chemistry during growth and dissolution. This new information can improve understanding of biogeochemical processes, including mineral dissolution and precipitation during biomineralization, as well as other processes such as scaling, carbon capture and storage and industrial $\mathrm{CaCO}_{3}$ production. Another goal was to help validate and constrain surface complexation models of the calcite surface (Morse, 1986; Van Cappellen et al., 1993; Fenter et al., 2000; Pokrovsky et al., 2000; VillegasJimenez et al., 2009), which normally do not include details of the atomic structure. Our modelling can predict behaviour for a variety of surface sites, which is useful for interpreting data from experiments, to help build surface complexation models and to improve understanding of mineral growth and dissolution.

\section{COMPUTATIONAL DETAILS}

All density functional theory (DFT) calculations were performed with the TURBOMOLE, 2011 program, v6.3 (Ahlrichs et al., 1989), using the BP functional (Perdew, 1986; Becke, 1988) and the TZVP basis set (Schafer et al., 1992; Weigend and Ahlrichs, 2005). The RI-J, with the multipole approximation, (Sierka et al., 2003) was used in all calculations. The COSMOtherm program, with the parameterization BP_TZVP_C30_1301, was used for all COSMORS calculations (Eckert and Klamt, 2002, 2013), using a temperature of $298 \mathrm{~K} . \mathrm{p} K_{\mathrm{a}}$ calculations in COSMO-RS have a root mean square deviation of $0.5 \mathrm{pH}$ units for molecules that are free in solution and are based on a linear free energy relationship between experimental $\mathrm{p} K_{\mathrm{a}}$ and the calculated free energy difference between the protonated and the deprotonated forms of the acid (Klamt et al., 2003). No explicit solvent molecules are required because hydrogen bonding is included in the COSMO-RS treatment.

The adsorption free energies for carbonate and bicarbonate ions were first calculated from the following gas phase reactions. Solvation effects were added later:
Inner sphere :

$$
\left(\text { calcite }-2 \mathrm{H}_{2} \mathrm{O}\right)+\mathrm{CO}_{3}^{2-} \rightarrow\left(\text { calcite- } \mathrm{CO}_{3}^{2-}\right)+2 \mathrm{H}_{2} \mathrm{O} \text { and }
$$

Outer sphere :

$$
\left(\text { calcite- } 2 \mathrm{H}_{2} \mathrm{O}\right)+\mathrm{CO}_{3}^{2-} \rightarrow\left(\text { calcite }-2 \mathrm{H}_{2} \mathrm{O}-\mathrm{CO}_{3}^{2-}\right) \text {. }
$$

In Eqs. (1) and (2), (calcite-X) refers to an 80 atom calcite cluster (Figs. 1 and 2) with adsorbed molecules, denoted $\mathrm{X}$. The two central $\mathrm{CaCO}_{3}$ units of the cluster viewed from the top (10 atoms) were relaxed along with all adsorbed molecules. Using our previous sensitivity analysis (Andersson and Stipp, 2011), we estimated that our 80 atom cluster should provide converged adsorption energies for carbonate and bicarbonate to within $10 \mathrm{~kJ} / \mathrm{mol}$. The error from the limited size of the cluster underestimates the adsorption energy by $\sim 10 \mathrm{~kJ} / \mathrm{mol}$.

The error from basis set superposition overestimates the adsorption energy by $\sim 10 \mathrm{~kJ} / \mathrm{mol}$, making for a fortuitous error cancellation. Adsorption of a carbonate ion onto an 80 atom cluster, alters the cluster charge from 0 to -2 , which gives an error of $5 \mathrm{~kJ} / \mathrm{mol}$ (included as part of the $10 \mathrm{~kJ} / \mathrm{mol}$ error estimate) (Andersson and Stipp, 2011).

To obtain the free energy of adsorption in solution, we calculated the free energy of solvation for each species using the reference state [1 bar gas/ 1 mol solvent] in COSMOtherm and added to the gas phase reaction energy. Solvation energies for divalent ions are reasonable and virtually free from systematic errors, even if individual errors are considerably higher than the mean absolute deviation $38 \mathrm{~kJ} / \mathrm{mol}$. (Andersson and Stipp, 2014). We also added the entropy contribution from translation, rotation and vibration. We calculated the entropy for free water, $\mathrm{CO}_{3}^{2-}$ and $\mathrm{HCO}_{3}^{-}$at the standard pressure of 1 bar using the harmonic approximation and standard expressions. The entropy of adsorbed ions was assumed to follow the empirical curve established using experimental data for gas phase adsorption by Campbell et al. (Campbell and Sellers, 2012), which states that

$S_{\text {ads }}=0.7 * S_{\text {free }}-3.3 R$.

$S_{\text {ads }}$ represents the entropy of the adsorbed molecule and $S_{\text {free, }}$, the entropy of the same molecule in the gas phase. Our reaction free energy thus excludes zero point energies but includes all other contributions to the free energy in solution. The assumption that the entropy of the adsorbed ions can be calculated from Eq. (3) remains to be validated and introduces another uncertainty to the adsorption energies. However, an adsorbed molecule should lose about $1 / 3$ of its translational entropy, regardless if it is adsorbed from gas or a liquid state.

We modelled the various surface sites of calcite using clusters created from the bulk structure, with experimental lattice parameters. We have shown that calcite clusters with 80 or more atoms provide converged $\mathrm{p} K_{\mathrm{a}}$ values for adsorbed water (Andersson and Stipp, 2012) so we used the same clusters in this study for the $\{10.4\}$ surface and for the acute and obtuse steps. For the kink sites, we created clusters consisting of 100 atoms, which had one additional molecular layer perpendicular to the step. Many bicarbonate geometries at the kink sites involve hydrogen 


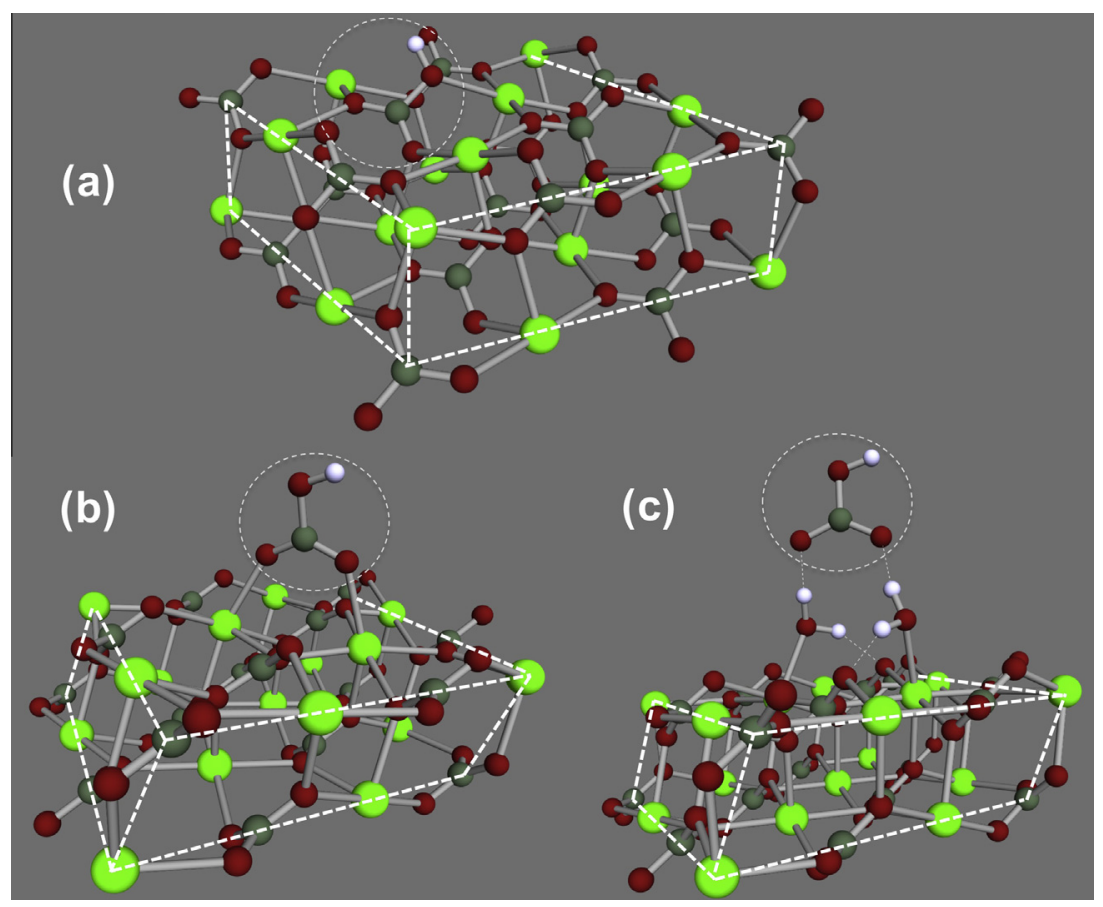

Fig. 1. Molecular structure for calcite cluster modelling for the bicarbonate interaction with calcite $\{10.4\}$, (a) as part of the surface, (b) adsorbed on the surface in an inner shell configuration, (c) adsorbed on calcite in an outer shell configuration. The front most calcite cluster edges are outlined with white dashed lines and the positions of the bicarbonate ions are indicated with grey dashed circles.

bonding of the bicarbonate $\mathrm{H}$ to an adjacent $\mathrm{CO}_{3}$. The larger clusters made sure that no bicarbonate hydrogen bond was made to $\mathrm{CO}_{3}$ group at the edge of the cluster because these $\mathrm{CO}_{3}$ groups are artificially uncoordinated and more prone to hydrogen bonding.

We kept most of the calcite cluster atoms frozen during the geometry optimizations but relaxed the protonated $\mathrm{CO}_{3}$ group and neighbouring $\mathrm{Ca}$ ions as long as they were not located at an edge of the cluster. This procedure resulted in converged $\mathrm{p} K_{\mathrm{a}}$ values for water adsorbed on calcite (Andersson and Stipp, 2012) so we assumed the same procedure could be applied for the bicarbonate-carbonate equilibrium.

\section{RESULTS}

The optimised molecular geometries for bicarbonate in and on the calcite $\{10.4\}$ plane are shown in Fig. 1. The optimised molecular geometry for bicarbonate in an acute step is presented in Fig. 2 and the optimised molecular geometry for bicarbonate in an obtuse kink is presented in Fig. 3. In Figs. 1-3, the positions of the bicarbonate are indicated with a dashed circle for clarity, as are the edges of the cluster and step edges on the cluster. All molecular geometries are included as $x y z$ files in the supporting information. All predicted $\mathrm{p} K_{\mathrm{a}}$ for bicarbonate deprotonation to carbonate are collected in Table 1. For adsorbed and incorporated bicarbonate, the $\mathrm{p} K_{\mathrm{a}}$ is lower than that of free bicarbonate in solution, which means that the presence of the calcite surface stabilizes carbonate relative to bicarbonate. The same surface preference of carbonate over bicarbonate can also be observed in Table 2, where the estimated free energies of adsorption of carbonate and bicarbonate are presented.

\section{DISCUSSION}

The COSMO-RS predicted $\mathrm{p} K_{\mathrm{a}}$ value for bicarbonate deprotonation to carbonate, i.e. $\mathrm{HCO}_{3}^{-}<=>\mathrm{CO}_{3}^{2-}+\mathrm{H}^{+}$, is 10.5 , which is in excellent agreement with the experimental value of 10.35 (Plummer and Busenberg, 1982) and provides confidence that the COSMO-RS method is applicable for our system. The $\mathrm{p} K_{\mathrm{a}}$ predicted for bicarbonate when it is integrated into the calcite surface, ranges from -6.0 to 2.4, depending on the surface site (Table 1). As for water adsorbed on Ca sites (Andersson and Stipp, 2012), there is a strong site dependence for protonation behaviour. It is worth noting that the uncertainties in the $\mathrm{pKa}$ of incorporated ions are most likely higher than for the free ions, because the assumption of bulk water surrounding the molecule is not valid at the surface, where strong hydration changes the water properties. Despite the large spread and higher uncertainty, the very low $\mathrm{p} K_{\mathrm{a}}$ values show one thing unambiguously: bicarbonate spontaneously deprotonates to carbonate when it associates with a calcite surface and protons prefer to be in the water phase at any $\mathrm{pH}$ for which calcite is stable. Our results are consistent with surface complexation models (Van Cappellen et al., 1993). The $\mathrm{p} K_{\mathrm{a}}$ from the calcite surface complexation model is 4.9 , but the surface concentration of bicarbonate is lower than adsorbed $\mathrm{Ca}$, which is not considered in this paper. The majority species in the surface complexation model would 


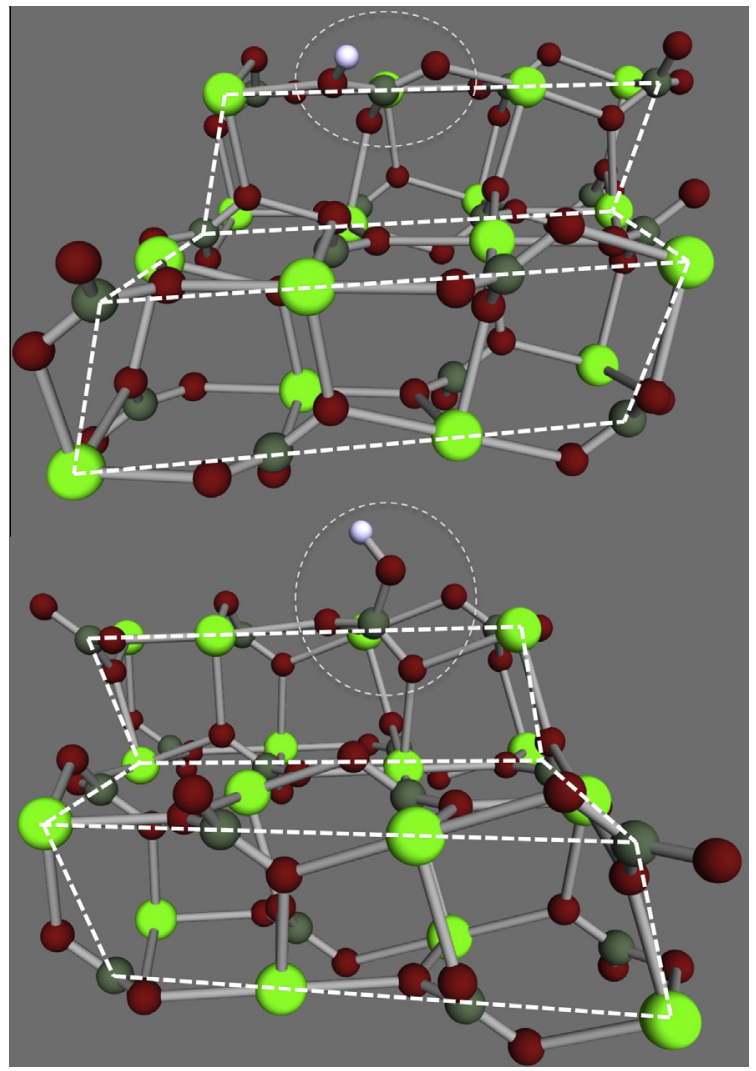

Fig. 2. Molecular structures for the clusters used to model bicarbonate when it is part of acute step sites on the calcite surface. The cluster is oriented so that the step is viewed at a slight angle from the $\{10.4\}$ plane towards the step. The front most calcite edges are outlined with white dashed lines and the positions of the bicarbonate ions are indicated with grey dashed circles.

hence not change with a lower $\mathrm{p} K_{\mathrm{a}}$, as suggested by our DFT calculations. In addition, the surface complexation model $\mathrm{p} K_{\mathrm{a}}$ is a surface average. Force field calculations
Table 1

Predicted $\mathrm{p} K_{\mathrm{a}}$ for the bicarbonate deprotonation reaction to carbonate, $\mathrm{HCO}_{3}^{-}<=>\mathrm{CO}_{3}^{2-}+\mathrm{H}^{+}$, at various surface sites of calcite. For the step and kink sites, there are two different orientations of the carbonate group and both $\mathrm{p} K_{\mathrm{a}}$ values are presented. The values are calculated for the case where there is no surface potential.

\begin{tabular}{lc}
\hline Site & $\mathrm{p} K_{\mathrm{a}}$ \\
\hline Free in solution & 10.35 \\
Adsorbed on $\{10.4\}$ (outer shell) & 7.4 \\
Adsorbed on $\{10.4\}$ (inner shell) & 7.5 \\
$\{10.4\}$ terrace & -6.0 \\
Acute step & $-5.6,-3.7$ \\
Obtuse step & $-5.0,-4.4$ \\
Kink site acute step, long $\mathrm{CO}_{3}^{-} \mathrm{CO}_{3}$ & $-2.6,-1.7$ \\
Kink site acute step, short $\mathrm{CO}_{3}^{-} \mathrm{CO}_{3}$ & $-4.0,2.4$ \\
Kink site obtuse step, long $\mathrm{CO}_{3}^{-} \mathrm{CO}_{3}$ & $-2.4,-1.8$ \\
Kink site obtuse step, short $\mathrm{CO}_{3}^{-} \mathrm{CO}_{3}$ & $-0.1,0.0$ \\
\hline
\end{tabular}

Table 2

Adsorption energy of carbonate from aqueous solution onto calcite $\{10.4\}$, modelled by an 80 atom calcite cluster in inner and outer sphere geometry.

\begin{tabular}{lc}
\hline Adsorption geometry & $\Delta G_{\text {ads }}(\mathrm{kJ} / \mathrm{mol})$ \\
\hline $\mathrm{CO}_{3}^{2-}$ on calcite $\{10.4\}$, outer shell & -50 \\
$\mathrm{HCO}_{3}^{-}$on calcite $\{10.4\}$, outer shell & -18 \\
$\mathrm{CO}_{3}^{2-}$ on calcite $\{10.4\}$, inner shell & 4 \\
$\mathrm{HCO}_{3}^{-}$on calcite $\{10.4\}$, inner shell & 34 \\
\hline
\end{tabular}

(Freeman et al., 2007; Wolthers et al., 2012) also demonstrated that bicarbonate would be unstable in the calcite $\{10.4\}$ surface.

The $\mathrm{p} K_{\mathrm{a}}$ for deprotonation of bicarbonate that is adsorbed on calcite $\{10.4\}$ is $3 \mathrm{pH}$ units lower than free bicarbonate deprotonation to carbonate, regardless of adsorption geometry (inner or outer sphere). The predicted adsorption energies suggest that outer shell adsorption is favoured over inner shell adsorption for both bicarbonate

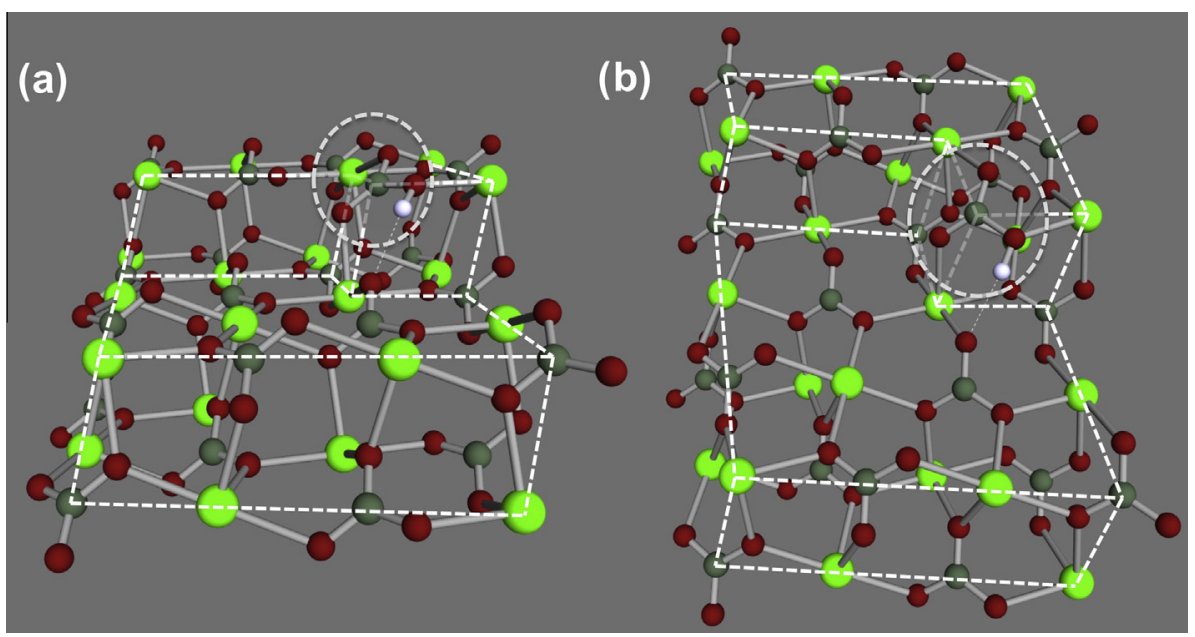

Fig. 3. Molecular structures for the calcite cluster used to model bicarbonate in an obtuse kink site in (a) side and (b) perspective view of the step. The front most calcite edges are outlined with white dashed lines and the positions of the bicarbonate ions are indicated with grey dashed circles. 
and carbonate (Table 2 and Fig. 1). That is, hydrogen bonding to bicarbonate and carbonate from the surface water molecules is more favourable than if the surface water is first removed and the species is bonded directly to the surface $\mathrm{Ca}$ ions. Because of the assumptions of how entropy is estimated, the adsorption energies should be viewed as qualitative, rather than quantitative.

The nature of the adsorbed species affects how the surface charge of calcite is influenced by the presence of bicarbonate, particularly if $\mathrm{pH}$ is $\leqslant 3 \mathrm{pH}$ units lower than the bicarbonate-carbonate solution $\mathrm{p} K_{\mathrm{a}}$, i.e. where $\mathrm{pH}$ is between 7.5 and 10.35 . This is the $\mathrm{pH}$ range where the bicarbonate-carbonate distribution in solution differs significantly from the distribution on the surface, i.e. $\mathrm{p} K_{\mathrm{a}}(\mathrm{ads})<\mathrm{pH}<\mathrm{p} K_{\mathrm{a}}(\mathrm{aq})$. In this $\mathrm{pH}$ range, most of the adsorbed bicarbonate ions would deprotonate into carbonate ions. From Table 2, we can also observe that the adsorption free energy for carbonate is $\sim 30 \mathrm{~kJ} / \mathrm{mol}$ stronger than the adsorption free energy of bicarbonate. The values reported in Table 2 indicate that our calculations overestimate the bond strength between the carbonate ion and the calcite surface. With such strong adsorption, the surface would be covered with carbonate ions, which is not what is observed in experiments (Fenter et al., 2000). However, the values in Table 2 are valid in the low coverage limit, and electrostatic repulsion between adsorbed ions would decrease the bond strength. The increased preference for carbonate over bicarbonate adsorbed on calcite means that even though the concentration of carbonate in solution is lower than bicarbonate, in the $\mathrm{pH}$ range $7.5-10.35$, the surface concentration of adsorbed carbonate is higher than adsorbed bicarbonate. This is an important result. It is consistent with carbonate being a potential determining ion for calcite (Stipp, 1999) and is also consistent with surface complexation models, which show that the surface concentrations of adsorbed $\mathrm{CO}_{3}$ and $\mathrm{HCO}_{3}$ are equal at $\mathrm{pH}=8.5$, which is lower than the $\mathrm{p} K_{\mathrm{a}}$ of free bicarbonate (10.33) (Van Cappellen et al., 1993; Pokrovsky et al., 2000). While surface complexation models are quite useful for simulating experimental results, they require fitting to a number of surface reactions. Our results require no fitting and can therefore be used to help constrain and validate calcite surface speciation models.

What are the implications for precipitation and dissolution of calcite from a molecular standpoint? We cannot rule out that bicarbonate is part of the incorporation and release mechanism for carbonate but we do predict that the stable form of the ion, when it is part of the surface, is the carbonate ion. We also note that some kink sites have a bicarbonate deprotonation $\mathrm{p} K_{\mathrm{a}}$ of 2.4 , meaning that even when $\mathrm{pH}$ is very low, if bicarbonate adsorbs, it deprotonates. Similar to water on $\mathrm{Ca}-\mathrm{Ca}$ kink sites (Andersson and Stipp, 2012), the protonation equilibrium of bicarbonate at $\mathrm{CO}_{3}-\mathrm{CO}_{3}$ kinks differs significantly from its equilibrium on the flat $\{10.4\}$ terraces. Mineral growth and dissolution are normally associated with addition and removal of ions to kink sites, which suggests that the carbonate-bicarbonate equilibrium for adsorbed ions predicted here plays an important role. Our results show that as long as there is equilibrium between carbonate and bicarbonate at all surface sites and as long as calcium dehydration is more energy consuming than (bi-)carbonate dehydration, only the carbonate ion needs to be considered when modelling calcite growth at $\mathrm{pH}>7$.

In Fig. 4, we show the two pathways for attaching (bi-) carbonate to a calcite step. The result of direct adsorption of carbonate into the calcite atomic structure (black arrow) is the same as the three step process: protonation to bicarbonate, adsorption of bicarbonate followed by deprotonation to carbonate (red arrow) so the free energy change is the same but the pathways are different. Because carbonate is a constituent ion of calcite, and bicarbonate is not, it is the chemical potential of carbonate that determines the saturation state for calcite, even though there are many more bicarbonate ions in solution. At constant $\mathrm{pH}$, increasing the bicarbonate concentration increases the carbonate concentration by the same factor and as a consequence increases the saturation state. The effect is particularly important in the $\mathrm{pH}$ range $7-10$ where the surface carbonate concentration is higher than the surface bicarbonate concentration. Increasing bicarbonate concentration thus reduces the thermodynamic driving force for dissolution and simultaneously increases the thermodynamic driving force for precipitation. This is consistent with bicarbonate acting as an inhibitor of calcite dissolution and a promoter of calcite growth (Przybylinski, 1987).

\section{CONCLUSIONS}

We have used the COSMO-RS method on 80-100 atom calcite clusters to predict the $\mathrm{p} K_{\mathrm{a}}$ of bicarbonate ions in calcite and adsorbed on the $\{10.4\}$ surface, i.e. terraces as well as step sites. When the bicarbonate is part of the surface, the $\mathrm{p} K_{\mathrm{a}}$ for deprotonation to carbonate ranges from -6.0 to 2.4 , depending on its surface environment, which implies that surface bicarbonate is unstable compared with surface carbonate at any $\mathrm{pH}$ for which calcite is stable. Outer sphere adsorption is predicted to be much more favourable than inner sphere adsorption. Our results demonstrate that the $\mathrm{pH}$ where adsorbed bicarbonate converts to carbonate is $3 \mathrm{pH}$ units lower than for bicarbonate deprotonation to carbonate in solution. This influences the surface charge in the $\mathrm{pH}$ range from 8 to 10 because $\mathrm{CO}_{3}^{2-}$, which is a potential determining ion for calcite, would adsorb at higher proportions than in the bulk solution. Our model, which is built on the fundamental properties of atoms

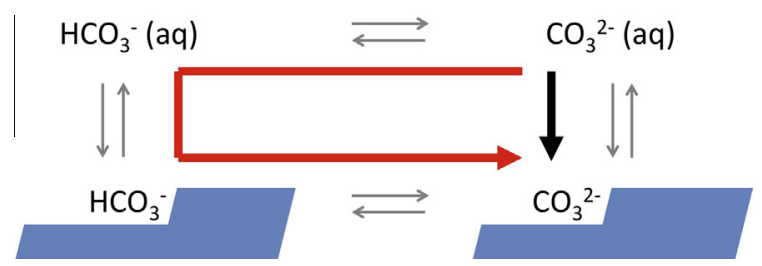

Fig. 4. Chemical equilibria for carbonate and bicarbonate ions in solution and on calcite surfaces. The black arrow is direct carbonate attachment to the surface, whereas the red arrow depicts the three step process: protonation to bicarbonate, adsorption of bicarbonate and subsequent deprotonation to carbonate. The reaction free energies for the two reactions are the same. 
and molecules, does not require experimental input. The results match well with existing experimental data so they are useful to help validate and constrain surface complexation models of the calcite surface and to predict behaviour in systems where experiments are quite difficult or impossible, such as at high temperature and pressure.

\section{ACKNOWLEDGEMENTS}

We are grateful for comments from two anonymous reviewers and we acknowledge funding from the Maersk Oil Research and Technology Centre. This work is also part of the Materials Interface with Biology (MIB) Consortium, which is funded through an UK EPSRC Grant (EP/I001514/1). This research was also supported by the NanoCArB Marie Curie Intra-European Fellowship (IEF) under contract PIEF-GA-2013-624016 to Juan Diego RodriguezBlanco. The computational resources were provided by the Danish Center for Scientific Computing (DCSC), which has since changed name to the Danish e-Infrastructure Consortium (DeIC).

\section{APPENDIX A. SUPPLEMENTARY DATA}

Supplementary data associated with this article can be found, in the online version, at http://dx.doi.org/10.1016/ j.gca.2015.12.016.

\section{REFERENCES}

Ahlrichs R., Bar M., Haser M., Horn H. and Kolmel C. (1989) Electronic-structure calculations on workstation computers the program system TURBOMOLE. Chem. Phys. Lett. 162, 165-169.

Andersson M. P. and Stipp S. L. S. (2011) Sensitivity analysis of cluster models for calculating adsorption energies for organic molecules on mineral surfaces. J. Phys. Chem. C 115, 10044 10055.

Andersson M. P. and Stipp S. L. S. (2012) How acidic is water on calcite? J. Phys. Chem. C 116, 18779-18787.

Andersson M. P. and Stipp S. L. S. (2014) Predicting hydration energies for multivalent ions. J. Comput. Chem. 35, 2070-2075.

Becke A. D. (1988) Density-functional exchange-energy approximation with correct asymptotic behavior. Phys. Rev. A 38, 3098-3100.

Berner R. A. (1990) Atmospheric carbon-dioxide levels over phanerozoic time. Science 249, 1382-1386.

Bohr J., Wogelius R. A., Morris P. M. and Stipp S. L. S. (2010) Thickness and structure of the water film deposited from vapour on calcite surfaces. Geochim. Cosmochim. Acta 74, $5985-5999$.

Campbell C. T. and Sellers J. R. V. (2012) The entropies of adsorbed molecules. J. Am. Chem. Soc. 134, 18109-18115.

Cassford G. E., House W. A. and Pethybridge A. D. (1983) Crystallization kinetics of calcite from calcium bicarbonate solutions between $278.15 \mathrm{~K}$ and $303.15 \mathrm{~K}$. J. Chem. Soc. Faraday Trans. 79, 1617-\&.

de Leeuw N. H., Parker S. C. and Harding J. H. (1999) Molecular dynamics simulation of crystal dissolution from calcite steps. Phys. Rev. B 60, 13792.

De Yoreo J. J., Zepeda-Ruiz L. A., Friddle R. W., Qiu S. R., Wasylenki L. E., Chernov A. A., Gilmer G. H. and Dove P. M. (2009) Rethinking classical crystal growth models through molecular scale insights: consequences of kink-limited kinetics. Cryst. Growth Des. 9, 5135-5144.
Duffy D. M., Travaille A. M., van Kempen H. and Harding J. H. (2005) Effect of bicarbonate ions on the crystallization of calcite on self-assembled monolayers. J. Phys. Chem. B 109, 57135718.

Eckert F. and Klamt A. (2002) Fast solvent screening via quantum chemistry: COSMO-RS approach. AIChE J. 48, 369-385.

Eckert, F., Klamt, A. (2013). COSMOtherm Version C3.0, Release 13.01, C3.0, Release 13.01 ed. COSMOlogic GmbH \& Co. KG, Leverkusen, Germany.

Feng J., Lee Y. J., Reeder R. J. and Phillips B. L. (2006) Observation of bicarbonate in calcite by NMR spectroscopy. Am. Mineral. 91, 957-960.

Fenter P. and Sturchio N. C. (2004) Mineral-water interfacial structures revealed by synchrotron X-ray scattering. Prog. Surf. Sci. 77, 171-258.

Fenter P., Geissbühler P., DiMasi E., Srajer G., Sorensen L. B. and Sturchio N. C. (2000) Surface speciation of calcite observed in situ by high-resolution X-ray reflectivity. Geochim. Cosmochim. Acta 64, 1221-1228.

Freeman C. L., Harding J. H., Cooke D. J., Elliott J. A., Lardge J. S. and Duffy D. M. (2007) New force fields for modeling biomineralization processes. J. Phys. Chem. C 111, 1194311951.

Gale J. D., Raiteri P. and van Duin A. C. T. (2011) A reactive force field for aqueous-calcium carbonate systems. Phys. Chem. Chem. Phys. 13, 16666-16679.

Gebrehiwet T. A., Redden G. D., Fujita Y., Beig M. S. and Smith R. W. (2012) The Effect of the $\mathrm{CO}_{3}^{2-}$ to $\mathrm{Ca}^{2+}$ ion activity ratio on calcite precipitation kinetics and $\mathrm{Sr}^{2+}$ partitioning. Geochem. Trans. 13.

Klamt A., Eckert F., Diedenhofen M. and Beck M. E. (2003) First principles calculations of aqueous $\mathrm{pK}(\mathrm{a})$ values for organic and inorganic acids using COSMO-RS reveal an inconsistency in the slope of the $\mathrm{pK}(\mathrm{a})$ scale. J. Phys. Chem. A 107, 9380-9386.

Lardge J. S., Duffy D. M. and Gillan M. J. (2009) Investigation of the interaction of water with the calcite (10.4) surface using ab initio simulation. J. Phys. Chem. C 113, 7207-7212.

Lardge J. S., Duffy D. M., Gillan M. J. and Watkins M. (2010) Ab initio simulations of the interaction between water and defects on the calcite $(10 \overline{1} 4)$ surface. J. Phys. Chem. C 114, 2664 2668.

Larsen K., Bechgaard K. and Stipp S. L. S. (2010a) The effect of the $\mathrm{Ca}^{2+}$ to $\mathrm{CO}_{3}^{2-}$ activity ratio on spiral growth at the calcite (10.4) surface. Geochim. Cosmochim. Acta 74, 2099-2109.

Larsen K., Bechgaard K. and Stipp S. L. S. (2010b) Modelling spiral growth at dislocations and determination of critical step lengths from pyramid geometries on calcite $(10 \overline{1} 4)$ surfaces. Geochim. Cosmochim. Acta 74, 558-567.

Lasaga A. C. and Luttge A. (2001) Variation of crystal dissolution rate based on a dissolution stepwave model. Science 291, 24002404.

Liang Y., Baer D. R., McCoy J. M., Amonette J. E. and LaFemina J. P. (1996) Dissolution kinetics at the calcite-water interface. Geochim. Cosmochim. Acta 60, 4883-4887.

MacKenzie F. T. and Andersson A. J. (2013) The marine carbon system and ocean acidification during phanerozoic time. Geochem. Perspect. 2, 1-227.

Millero F. J. (2003) Physicochemical Controls on Seawater. Elsevier.

Morse J. W. (1986) The surface chemistry of calcium carbonate minerals in natural waters: an overview. Mar. Chem. 20, 91112.

Nimer N. A. and Merrett M. J. (1992) Calcification and utilization of inorganic carbon by the coccolithophorid emiliania-huxleyi lohmann. New Phytol. 121, 173-177. 
Nimer N. A., IglesiasRodriguez M. D. and Merrett M. J. (1997) Bicarbonate utilization by marine phytoplankton species. $J$. Phycol. 33, 625-631.

Paasche E., Brubak S., Skattebol S., Young J. R. and Green J. C. (1996) Growth and calcification in the coccolithophorid Emiliania huxleyi (Haptophyceae) at low salinities. Phycologia 35, 394-403.

Perdew J. P. (1986) Density-functional approximation for the correlation energy of the inhomogeneous electron gas. Phys. Rev. B Condens. Matter 33, 8822-8824.

Plummer L. N. and Busenberg E. (1982) The solubilities of calcite, aragonite and vaterite in $\mathrm{CO}_{2}-\mathrm{H}_{2} \mathrm{O}$ solutions between 0 and $90^{\circ} \mathrm{C}$, and an evaluation of the aqueous model for the system $\mathrm{CaCO}_{3}-\mathrm{CO}_{2}-\mathrm{H}_{2} \mathrm{O}$. Geochim. Cosmochim. Acta 46, 1011-1040.

Pokrovsky O. S., Mielczarski J. A., Barres O. and Schott J. (2000) Surface speciation models of calcite and dolomite/aqueous solution interfaces and their spectroscopic evaluation. Langmuir 16, 2677-2688.

Przybylinski J. L. (1987) The role of bicarbonate ion in calcite scale formation. SPE Prod. Eng. 2, SPE-13547-PA.

Raiteri P. and Gale J. D. (2010) Water is the key to nonclassical nucleation of amorphous calcium carbonate. J. Am. Chem. Soc. 132, 17623-17634.

Reddy M. M., Plummer L. N. and Busenberg E. (1981) Crystalgrowth of calcite from calcium bicarbonate solutions at constant $\mathrm{P}_{\mathrm{CO} 2}$ and 25-degrees-C. a test of a calcite dissolution model. Geochim. Cosmochim. Acta 45, 1281-1289.

Reeder R. J. (1992) Carbonates - growth and alteration microstructures. Rev. Mineral. 27, 381-424.

Schafer A., Horn H. and Ahlrichs R. (1992) Fully optimized contracted gaussian-basis sets for atoms $\mathrm{Li}$ to $\mathrm{Kr}$. J. Chem. Phys. 97, 2571-2577.

Sierka M., Hogekamp A. and Ahlrichs R. (2003) Fast evaluation of the Coulomb potential for electron densities using multipole accelerated resolution of identity approximation. J. Chem. Phys. 118, 9136-9148.

Stipp S. L. S. (1999) Toward a conceptual model of the calcite surface. Hydration, hydrolysis, and surface potential. Geochim. Cosmochim. Acta 63, 3121-3131.

Stipp S. L. and Hochella M. F. (1991) Structure and bonding environments at the calcite surface as observed with X-ray photoelectron spectroscopy (XPS) and low energy electron diffraction (LEED). Geochim. Cosmochim. Acta 55, 1723-1736.

Tribello G. A., Bruneval F., Liew C. and Parrinello M. (2009) A molecular dynamics study of the early stages of calcium carbonate growth. J. Phys. Chem. B 113, 11680-11687.

TURBOMOLE V6.3. (2011). A development of University of Karlsruhe and Forschungszentrum Karlsruhe GmbH, 19892007, TURBOMOLE GmbH, since 2007.

Van Cappellen P., Charlet L., Stumm W. and Wersin P. (1993) A surface complexation model of the carbonate mineral-aqueous solution interface. Geochim. Cosmochim. Acta 57, 3505-3518.

van der Weijden R. D., van der Heijden A. E., Witkamp G. J. and van Rosmalen G. M. (1997) The influence of total calcium and total carbonate on the growth rate of calcite. J. Cryst. Growth 171, 190-196.

Villegas-Jimenez A., Mucci A., Pokrovsky O. S. and Schott J. (2009) Defining reactive sites on hydrated mineral surfaces: rhombohedral carbonate minerals. Geochim. Cosmochim. Acta 73, 4326-4345.

Wallace A. F., Hedges L. O., Fernandez-Martinez A., Raiteri P., Gale J. D., Waychunas G. A., Whitelam S., Banfield J. F. and De Yoreo J. J. (2013) Microscopic evidence for liquid-liquid separation in supersaturated $\mathrm{CaCO}_{3}$ solutions. Science 341, 885-889.

Weigend F. and Ahlrichs R. (2005) Balanced basis sets of split valence, triple zeta valence and quadruple zeta valence quality for $\mathrm{H}$ to $\mathrm{Rn}$ : design and assessment of accuracy. Phys. Chem. Chem. Phys. 7, 3297-3305.

Wolthers M., Di Tommaso D., Du Z. and de Leeuw N. H. (2012) Calcite surface structure and reactivity: molecular dynamics simulations and macroscopic surface modelling of the calcitewater interface. Phys. Chem. Chem. Phys. 14, 15145-15157.

Zeebe R. E. (2011) On the molecular diffusion coefficients of dissolved $\mathrm{CO}_{2}, \mathrm{HCO}_{3}^{-}$, and $\mathrm{CO}_{3}^{2-}$ and their dependence on isotopic mass. Geochim. Cosmochim. Acta 75, 2483-2498.

Zeebe R. E. and Wolf-Gladrow D. (2001) $\mathrm{CO}_{2}$ in Seawater: Equilibrium, Kinetics, Isotopes. Elsevier.

Associate editor: Bjorn Jamtveit 